\section{Commentary: Time is muscle}

\author{
Christoph Haller, MD
}

Postoperative coronary artery complications are rare but dire events after repair of congenital heart disease. In this issue of the Journal, Goldsmith and colleagues ${ }^{1}$ present an important study on postoperative angiography in patients with coronary artery obstruction. The authors identified all pediatric patients with postoperative obstructive coronary artery lesions on angiography over a time span of more than 15 years. They assessed the timing of angiography and subsequent intervention relative to the sentinel event at which a significant deviation from the clinical course raised the suspicion of coronary artery compromise and identified delay as a risk factor for death or transplantation listing. The study nicely delineates that early diagnosis and intervention are crucial to prevent death or persistent myocardial dysfunction. Patients with hypoplastic left heart syndrome had an increased risk of death or listing for transplantation.

In patients with congenital heart surgery, we frequently perform complex procedures that involve coronary arteries either directly or that are at risk of compromising coronary perfusion indirectly. If myocardial blood flow is impaired, the consequences are usually devastating and mandate swift action. However, in congenital cases, the invasive diagnostic armamentarium is commonly used more conservatively compared with adult patients with acquired coronary artery lesions. Echocardiography provides excellent imaging of the proximal coronary arteries and can frequently rule out major obstruction. Invasive angiography, especially in very small patients, also comes with procedural risk, such as peripheral vascular complications, severe arrhythmia, and injury of the heart or great vessels, although the procedure can be considered safe. ${ }^{2}$ The options to intervene for coronary artery lesions can be limited. The study by Goldsmith and colleagues disproves a conservative approach, clearly highlighting the importance of maintaining a low threshold of suspicion for

From the Department of Cardiovascular Surgery, The Labatt Family Heart Centre, The Hospital for Sick Children, University of Toronto, Toronto, Ontario, Canada. Disclosures: Author has nothing to disclose with regard to commercial support.

Received for publication Nov 13, 2019; accepted for publication Nov 13, 2019; available ahead of print Jan 16, 2020

Address for reprints: Christoph Haller, MD, Division of Cardiovascular Surgery, The Hospital for Sick Children, 555 University Ave, Toronto, Ontario, Canada, M5G 1X8 (E-mail: christoph.haller@sickkids.ca).

J Thorac Cardiovasc Surg 2020;159:1968-9

$0022-5223 / \$ 36.00$

Copyright (c) 2019 by The American Association for Thoracic Surgery

https://doi.org/10.1016/j.jtcvs.2019.11.072

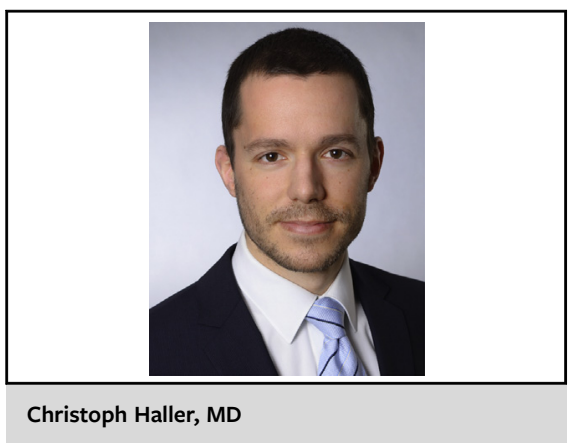

CENTRAL MESSAGE

Early detection of impaired

myocardial blood flow is crucial

and should lower the threshold

for invasive diagnostic

investigation.

coronary artery lesions and for early diagnostic confirmation thereof.

The severity of myocardial dysfunction in the study population is reflected by a $79 \%$ incidence of extracorporeal membrane oxygenation (ECMO) support at the time of catheterization and a mortality of $41 \%$ before hospital discharge. We have previously shown that early cardiac catheterization in patients on ECMO improves outcomes despite the relatively high procedural morbidity. ${ }^{3}$ Clinical decision making for or against coronary angiography in patients with clear signs of myocardial dysfunction and a high likelihood of an underlying coronary artery lesion is unequivocal; however, decision making is more complex after cardiac procedures that carry a low risk for coronary artery compromise and in patients with atypical clinical signs that are not easily attributed to coronary malperfusion alone. This study offers only a limited view on a patient population that was selected based on the presence of the coronary artery lesion itself.

Two aspects remain to be investigated further to guide clinicians in determining when to aggressively push for invasive coronary artery imaging and when to ward off a potentially unnecessary and harmful procedure. An analysis of echocardiographic imaging of the coronary arteries compared with coronary angiography is needed to define whether normal echocardiography results are sufficient to rule out coronary morbidity. Furthermore, the study population should be expanded to include all postoperative coronary angiographies irrespective of the confirmation of coronary artery lesions and to thoroughly describe the risk profile of the procedure. Both of these aspects would 
complete the picture and define risks and benefits more precisely.

Goldsmith and colleagues are clearly building the case for early diagnostic coronary angiography in patients with suspicion for myocardial ischemia after congenital cardiac surgery. Despite the poor outcome of coronary artery obstruction, it is encouraging that the majority of lesions were anatomic and amenable to intervention. Similar to the proven benefit of early intervention in adults with myocardial infarction, ${ }^{4}$ it is time to strengthen the old paradigm of "time is muscle" in pediatric patients as well.

\section{References}

1. Goldsmith MP, Allan CK, Callahan R, Kaza AK, Mah DY, Salvin JW, et al. Acute coronary artery obstruction following surgical repair of congenital heart disease. $J$ Thorac Cardiovasc Surg. 2020;159:1957-65.e1.

2. Vranicar M, Hirsch R, Canter CE, Balzer DT. Selective coronary angiography in pediatric patients. Pediatr Cardiol. 2000;21:285-8.

3. Kato A, Lo Rito M, Lee KJ, Haller C, Guerguerian AM, Sivarajan VB, et al. Impacts of early cardiac catheterization for children with congenital heart disease supported by extracorporeal membrane oxygenation. Catheter Cardiovasc Interv. 2017:89:898-905.

4. Park J, Choi KH, Lee JM, Kim HK, Hwang D, Rhee TM, et al Prognostic implications of door-to-balloon time and onset-to-door time on mortality in patients with ST-segment-elevation myocardial infarction treated with primary percutaneous coronary intervention. J Am Heart Assoc. 2019;8: e012188.
See Article page 1957.

\section{Commentary: Survival after coronary injury — it's about time}

\section{Ibrahim Abdullah, MD, and Zohair Al-Halees, MD}

In this issue of the Journal, Porras and colleagues ${ }^{1}$ present $^{-}$ the largest retrospective series of this era from a single institution analyzing acute coronary artery obstruction (CAO) following congenital heart disease surgery. It is noteworthy that out of 13,370 patients with congenital heart disease (CHD) who underwent open heart surgery requiring cardiopulmonary bypass (CPB), only 37 were found to have acute postoperative CAO. Out of these, 34 were analyzed. Although this represents a very small number from such a large population, the consequences of acute postoperative CAO remain devastating, with $79 \%$ of the patients requiring extracorporeal membrane oxygenation (ECMO) support at the time of cardiac catheterization, 59\% experiencing a composite outcome of mortality or listing for transplantation, and a $41 \%$ mortality rate at discharge. Despite these humbling statistics associated with acute postoperative $\mathrm{CAO}$, the authors validate the importance of early recognition and intervention.

\footnotetext{
From the Department of Pediatric Cardiac Surgery, King Faisal Specialist Hospital \& Research Center, Riyadh, Saudi Arabia.

Disclosures: Authors have nothing to disclose with regard to commercial support. Received for publication Nov 1, 2019; revisions received Nov 1, 2019; accepted for publication Nov 1, 2019; available ahead of print Jan 22, 2020.

Address for reprints: Ibrahim Abdullah, MD, Department of Pediatric Cardiac Surgery, King Faisal Specialist Hospital \& Research Center, Riyadh, Saudi Arabia (E-mail: iabdullah1234@gmail.com).

J Thorac Cardiovasc Surg 2020;159:1969-70

$0022-5223 / \$ 36.00$

Copyright (C) 2019 by The American Association for Thoracic Surgery

https://doi.org/10.1016/j.jtcvs.2019.11.027
}

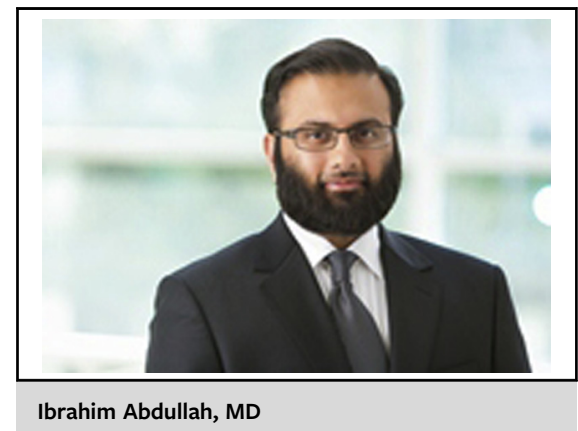

CENTRAL MESSAGE

Survival after postoperative coronary artery obstruction for congenital heart disease is dependent on timely recognition and intervention.

In their analysis, patients who experienced the foregoing composite outcome had significantly longer (more than double to almost triple) sentinel event to catheterization times, as well as significantly longer times from sentinel event to intervention. Furthermore, it is interesting to note that in their review, $65 \%$ of the operative notes raised no coronary concerns. Perhaps this is why a sentinel event, as defined by the authors, served as the starting point from which to measure the time to catheterization and intervention.

Our experience with acute postoperative $\mathrm{CAO}$ at the King Faisal Specialist Hospital and Research Center anecdotally mirrors the experience of the authors. The vast majority of such complications, although infrequent, have been associated with operations in which there has been direct technical 